\title{
Linguistic structures emerging in the synchronization of a Pilates class
}

Leelo Keevallik

The self-archived postprint version of this journal article is available at Linköping University Institutional Repository (DiVA):

http://urn.kb.se/resolve?urn=urn:nbn:se:liu:diva-168934

N.B.: When citing this work, cite the original publication.

Keevallik, L., (2020), Linguistic structures emerging in the synchronization of a Pilates class, Moblizing Others, , 147-173. https://doi.org/10.1075/slsi.33.o6kee

Original publication available at:

https://doi.org/10.1075/slsi.33.06kee

Copyright: John Benjamins Publishing Company

https://benjamins.com/content/home 
Linguistic structures emerging in the synchronization of a Pilates class

Running head: Synchronizing a Pilates class

Leelo Keevallik,

Department of Culture and Communication

Linköping University

Linköping 58183

Sweden

leelo.keevallik@liu.se

\begin{abstract}
This chapter targets grammar in the interactive process between a Pilates teacher and the exercising students, an activity context in which instruction and compliance can be designed to merge in time. It shows how linguistic structure, such as counts, formula, and phrases, emerges step-by-step sensitively to the others' currently moving bodies. At the same time, the situation-designed structures direct the students through the partially known moves. In contrast to formal theories that consider grammar as a device for coherent expression of propositions, this study argues that grammatical structure emerges through recurrent use in a specific activity context. The video-recorded data is in Estonian.
\end{abstract}

\title{
Keywords
}

interactional linguistics, embodiment, instruction, emergent grammar, rhythm, synchronization, Estonian, formula, counting, repetition

\section{Introduction}

Several influential theories during the past century have treated grammar as a self-contained hierarchical structure that is capable of expressing coherent propositions. Motivations for the structure have therefore been sought within the system itself (see the discussion by Linell 2009). In contrast, functionalist theories have been explaining features of grammar as motivated by factors outside the system (Bybee 2003). This chapter targets the local emergence of grammar as affected by body movements by self and other, while the speaker is instructing the recipients in a Pilates class, and asks how embodied behavior and intersubjective coordination should figure in our description of grammar.

One branch of functionalism that has taken a determined stance against formalist reductionism is interactional linguistics, established as a rigorously empirical research endeavor around the turn of the millennium (Couper-Kuhlen and Selting 2018; Ochs et al. 1996; Selting and Couper-Kuhlen 2001). Methodologically it relies on conversation analysis, which has been recently pedagogically summarized in Clift (2016). Interactional linguistics embraces 
all the basic conversation analytic findings on the turn-taking system and, crucially for linguistics, the nature of temporally emerging and negotiable turnconstructional units (Sacks et al. 1974). Analytically, it profits from the research on the sequential organization of conversational actions (Schegloff 2007), which enables studying the systematicity between syntactic form and its function as oriented to by participants. The current chapter will build methodologically on this research into sequential action, but also problematize the sequential relationship between directivity and responsivity by demonstrating that there are complex temporalities in play between the speaking teacher and the students' moving bodies, at least in instructional activities. It looks at how other bodies are mobilized to move moment-bymoment, achieving the local social order of a Pilates class.

In numerous spoken as well as written activity contexts, we produce grammar in real time. Therefore, the precise emergence of linguistic patterns (Hopper 1998) should be of central theoretical interest for linguists to counterbalance the formal and often excessively hierarchical models of recalled or imagined atemporal sentences (Linell 2009). As interacting human beings, we cannot rely merely on our earlier experiences of lexicon and grammar, because this abstracted knowledge does not in itself guarantee mutual understanding in the here and now. Furthermore, language is but one resource of sense-making. Through the recent "embodied turn" in research on language and social interaction (Nevile 2015), there has been growing awareness of the role of the body in achieving mutual understanding. A more realistic view on how intersubjectivity is achieved can be found in the complex interplay between language, body movements, and the material environment (Streeck et al. 2011). Both social action formation and the emergence of grammatical structure are essentially multimodal processes. For example, the current analysis cannot ignore the role of the exercising bodies in sense-making. The students' bodies form the very basis of the entire activity, and are supported by the teacher's verbal, vocal, and bodily practices. The mutual coordination and constant fine adjustment of verbal and bodily moves, and the ultimate achievement of synchrony between the vocal-bodily actions of the teacher and the bodily actions of the students, will be the subject of the chapter.

In different instructional activities which essentially target the body, such as dance classes and driving schools, we have already been able to discover grammatical regularities. For example, Estonian 'no'-prefaced turns describe students' mistakes in dance classes (Keevallik 2012). A study of a Swiss Italian driving school has demonstrated the dependence of grammatical formats on the timing of the instruction: the "early" instructions involved verbs while the "late" ones did not (DeStefani and Gazin 2014). The grammatical systematicity of all these actions stems from the fact that they immediately react to, and project, the other's embodied behavior, which undermines the formal perspective on grammar as the combining of linguistic elements to express a proposition. Characteristically, in the context of instructing another body, teacher directives can partially overlap the students' responses, as has been shown in Swedish dance classes (Broth and Keevallik 2014). Furthermore, the teachers may systematically aim for the synchronization of their talk and vocalizations with their own moves (Keevallik 2015). In the current chapter, 
we will be exploring the teacher's vocal practices of mobilizing others to perform moves on time and together, focusing on the emergence of grammatical elements such as nouns, verbs, particles, phrases, and case endings in this process. These structures will be discussed within the framework of major strategies of synchronization of the talk and the bodies: counting, formula repetition, as well as the emergence of movements together with the elements within an adverbial phrase. The chapter will look at each of these teacher practices in the above order.

\section{The data}

The data come from a video-recording of an hour-long Pilates class in Estonian, offered at a club where students may have quite different levels of experience. In this class, however, they cannot be absolute beginners, which facilitates the usability of the strategies described below. Besides knowledge about how instructions are given, the students may have some idea of the customary progression of the class. Occasionally the teacher comments on something being new, but this can also happen when the exercise is already in progress or even after its completion, so that the students have already been guided into the exercise. Even though the students can sometimes project what should be done next, the exact pace of single moves, exercises and transitions between them are locally established in the interplay between the teacher and the students. The exercises consist of repetitive moves, and sometimes several rounds of the same move on different sides, with opposite limbs, etc. These repetitions create an activity-specific rhythm, such as legs kicking back and forth or bodies moving up and down in consecutive executions of the same exercise. In this chapter, rhythm is thus understood to be a primarily embodied matter, albeit also synchronized with and through language.

Pilates is a fitness system which focuses on strength and stamina and which aims at an economic flow of movement, including elegant transitions from one exercise to the next. It makes essential use of breathing, which can be seen in the excerpts below. There is no music playing, as is otherwise often the case in, for instance, yoga classes, and this makes the activity setting especially interesting for the analysis of language and grammar. The pace of the class and rhythms of the exercise are created here entirely in the interplay between the teacher's voice and the moving bodies. The study is based on a collection of all instances where the teacher's utterance targets the move which is to be (near)simultaneously performed by the students. It contains around two hundred single words, phrases, clauses, and non-grammatical formula (as explained below). The participants have agreed to the use of the data for research purposes.

\section{Counting and synchronization}

One of the most straightforward synchronization devices in different kinds of physical training is counting. As has been shown in an earlier study on dance instruction, the teachers can accomplish a transition from instruction to practice 
by using a count-in, such as five (.) six (.), five six seven eight, at the end of which the students are supposed to make the first dance move (Broth and Keevallik 2014). In addition, as will be discussed here, the teachers may count throughout the students' practice. Differently from a count-in, the first number is here supposed to be in synchrony with the first move of the exercise, as shown in example (1). The students have made themselves more or less ready for the next exercise, sitting with straight spines. During line (1) they are stretching their arms to the side, which the last three students manage to do by the word sisse 'in' in line (2). This preparation does not have to be in synchrony with others but it has to be completed by the beginning of the exercise, which is itself prompted by the label selja pööramine 'spine rotation' (line 1). The essential Pilates breathing instruction in line (2) is produced rapidly while the gerund välja ingates 'while breathing out' suggests that the outbreath will need to happen simultaneously with the exercise which is just about to begin. Line 2 ends in an unfinished prosodic contour ${ }^{1}$, indexing continuation. The teacher starts turning her upper body on välja 'out', and the first students follow on ingates 'breathing'. Others follow (either the count, the teacher's body, or other students) and before the first number üks 'one' has come to an end, everybody is turning. The first move of the exercise - the spinal twist to the right - is thus accompanied with the count in line (3), as can also be seen in Figure \#1. Amplitude and pitch curves are aligned with word beginnings in the transcripts.

(1)

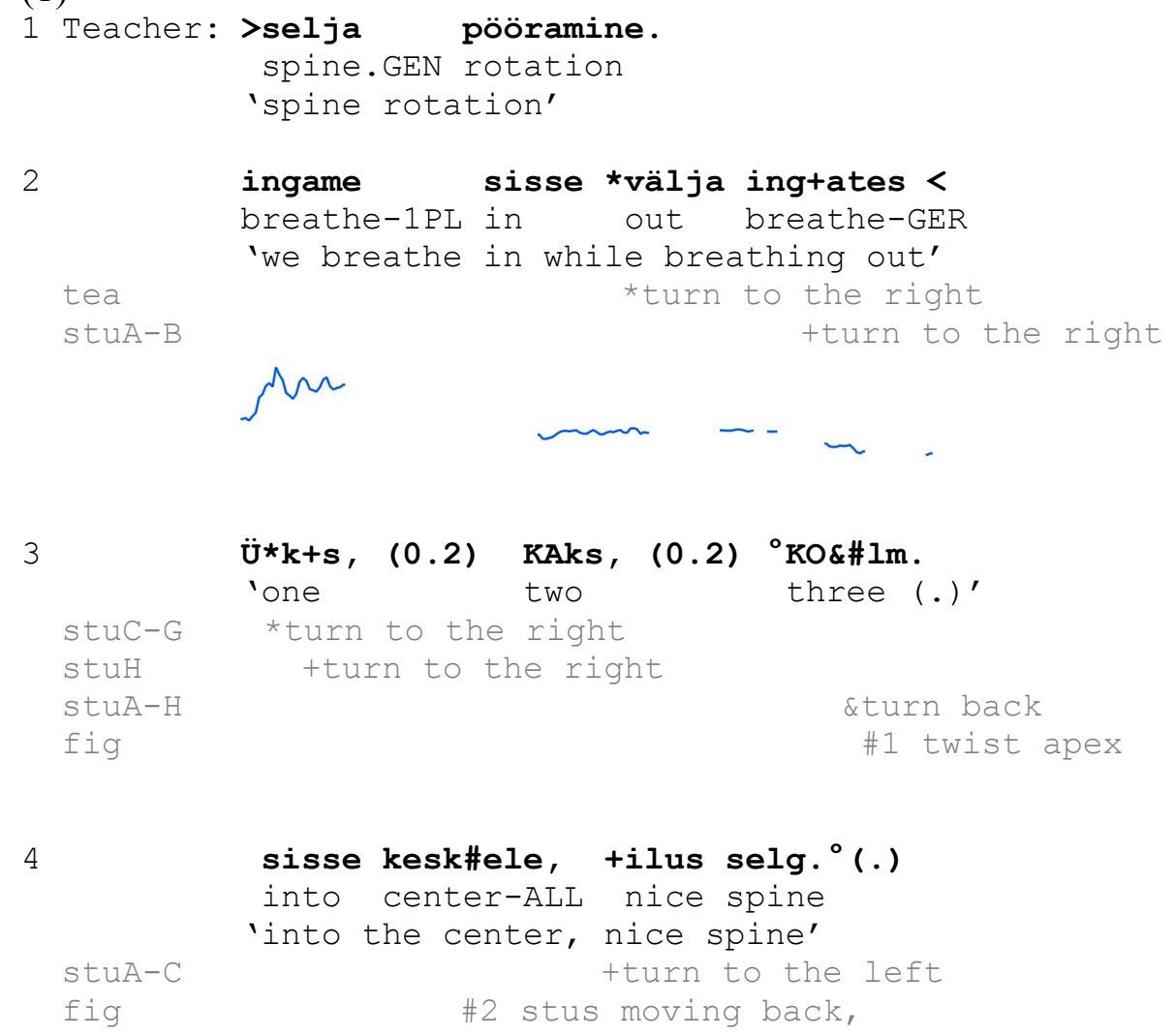

${ }^{1}$ Note that only terminated intonation contours are marked in the transcript. When there is no punctuation mark, the contour is not terminated. 


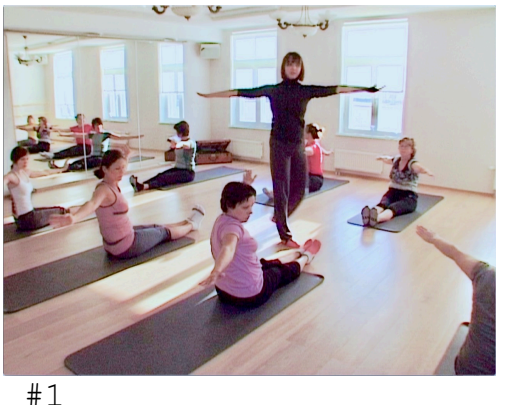

$\# 1$

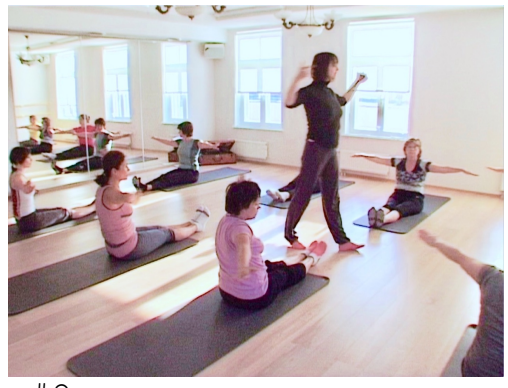

\#2

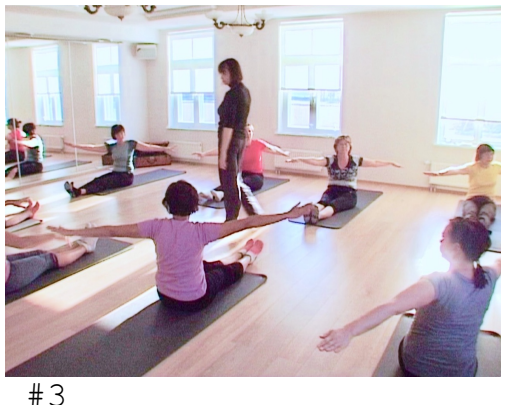

\#3

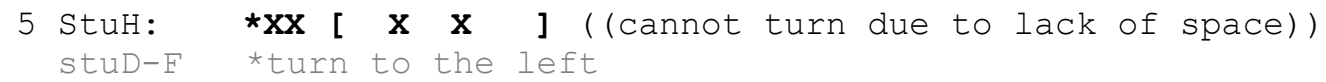

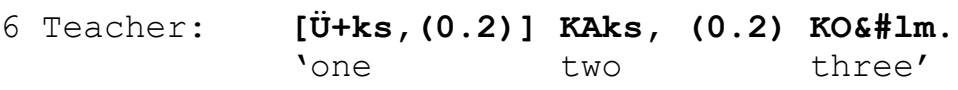

stuG

turn to the left

stuA-G

\&turn back

\#3 twist apex

A number of prosodic features separate the count from the rest of the talk. Line

(3) is slower, more accentuated, and louder than previous talk, and the numbers are interchanged with pauses, which results in a distinct rhythmic quality.

Furthermore, at the beginning of kolm 'three' the pitch starts moving downwards, projecting a termination (because of half-whisper on this word, the last part of the pitch curve is not visible in the Praat drawing). Exactly during this single-syllable word, the body turn to the right also features its apex (as represented in Figure \#1): the teacher as well as the students start turning back towards the center. Crucially, there is no objective reason for the count in this case to be exactly up to the number three (for example, nothing in particular happens on 'two', the movement simply continues). Instead, this seems to be an epiphenomenal result of the assumed and actual length of the participants' spine twist to one side and the chosen vocal rhythm of the count. It could as well have been 'one, two', or 'one, two, three, four', depending on the pace of counting that the teacher chooses, because any of these options can be produced rhythmically. Importantly, the count has here emerged in synchrony with the moving bodies, partially organizing it, but also tuning in to the concurrent movement by the students. It is thus also a reflexive device for designing the talk and body movements as synchronous.

The teacher then abandons her demonstration of the exercise and provides a corrective instruction in quick half-whisper ilus selg 'nice spine' (in line 4), while pointing at her shoulders (Figure \#2 shows her arm movement towards the point). During this time, the students turn their torsos back to the center and three of them continue the move to the other side, displaying their ability to project the next segment of the exercise. The counting is re-launched in line (6) with the same rhythm as before, same numbers, same voice level, same intonational features (the pitch curve picture is compromised because of the overlap), although without the teacher's demonstrating body. She is now walking in the middle of the sitting students (see Figure \#3). This repetition of 
the precise count format suggests that the exercise has to be continued in an identical manner to the opposite side. However, for the students it emerges as a simultaneous confirmation of what they have already been doing from the very beginning of the count. As in the prior turn to the right, the turn to the left has its movement apex exactly on KOlm 'three' (in line 6, Figure \#3). At the apexes, the entire class is acting in absolute synchrony: the teacher's word coincides with the students' extreme body position. This is an illustration of the synchronizing power of a count, with or without the teacher's own demonstration. The counting itself, the repetition of the same sequence of numbers, as well as the rhythm and intonation are all central for this pattern of speaking to work as a temporal organizer of a repetitive practice.

The main prerequisite for the count to work is projectability: the ability of the students to project what is expected during the uttering of essentially uninformative numbers. The exercise was launched by preparatory moves (data not shown), an exercise label (line 1), breathing instruction, prosodic incompletion, and specific grammar (imperative, gerund) in line (2). After seeing and hearing the first segment of the exercise in line (3), even a novice could make a reasonable guess about what should happen next. In any case, a designed synchrony emerged across lines (3-6) of this excerpt, where a count was involved in the intersubjective accomplishment of a joint rhythm between the speaking teacher and the practicing students, with the teacher's uttering of the word kolm 'three' temporally coinciding with the movement apex of the students in the class. Counts can be repeated, as shown above with üks kaks kolm 'one two three', but so can other verbal materials. This will be the subject of the following section, where we will also return to a different synchronization strategy with numbers, specifically the countdown (after excerpt 3).

\section{Formula repetition and synchronization}

Frequent repetition seems to be one of the main characteristics of speech in a Pilates class. Repetition has been studied for its various functions in discourse (Tannen 1987, 1989) and in conversation, such as when responding (Bolden 2009), reassuring (Keevallik 2010a) or when displaying understanding (Betz et al. 2013; Svennevig 2004, 2008). While in conversation analytic studies mostly other-repetition has been of interest (see, however, Curl et al. 2006), the current activity of a Pilates class features abundant self-repetition by the teacher. It is basically used to direct the others' bodies rhythmically through a repetitive series of an exercise. Self-repetitions in Pilates instruction are indexical and build on a previously established (possibly partial) understanding of the course of an exercise, as was also argued after excerpt (1). Apart from counts, repetitions may feature a variety of linguistic formats (such as nouns in various cases, adverbs, or imperatives in the singular or plural), characteristically built out of segments of the initial instruction. In this section we will first look at how a formula is locally established in the activity, and then move from less to more complex verbal formulas. 
Excerpt (2) shows an instance of how a formula is established after transition to an exercise which entails rolling onto one's back. The excerpt starts with an instruction on how to breathe during the different stages of the roll (lines 1-4). Slightly before line (4) has come to an end, the first student already begins to move down (Figure \#4, the student at the left edge). The second one moves backward on the last word of the imperative phrase hinga välja 'breathe out'. Others follow in line (6). The students thus comply immediately upon the termination of the instruction. The teacher waits until everybody has started rolling and then initiates a gesture inward, after which she utters the instruction for the return to start position ing $a^{2}$ sisse 'breathe in' (line 8). All the students (apart from the early one on the left, stuA) come up immediately after the end of the utterance; thus, a rhythm has been established for the exercise. However, possibly because the balance in this exercise is trickier than in excerpt (1) and some students skip rounds, we cannot observe the precise synchrony of the bodies. This makes it especially clear that intersubjective synchrony is a local social achievement.

(2)

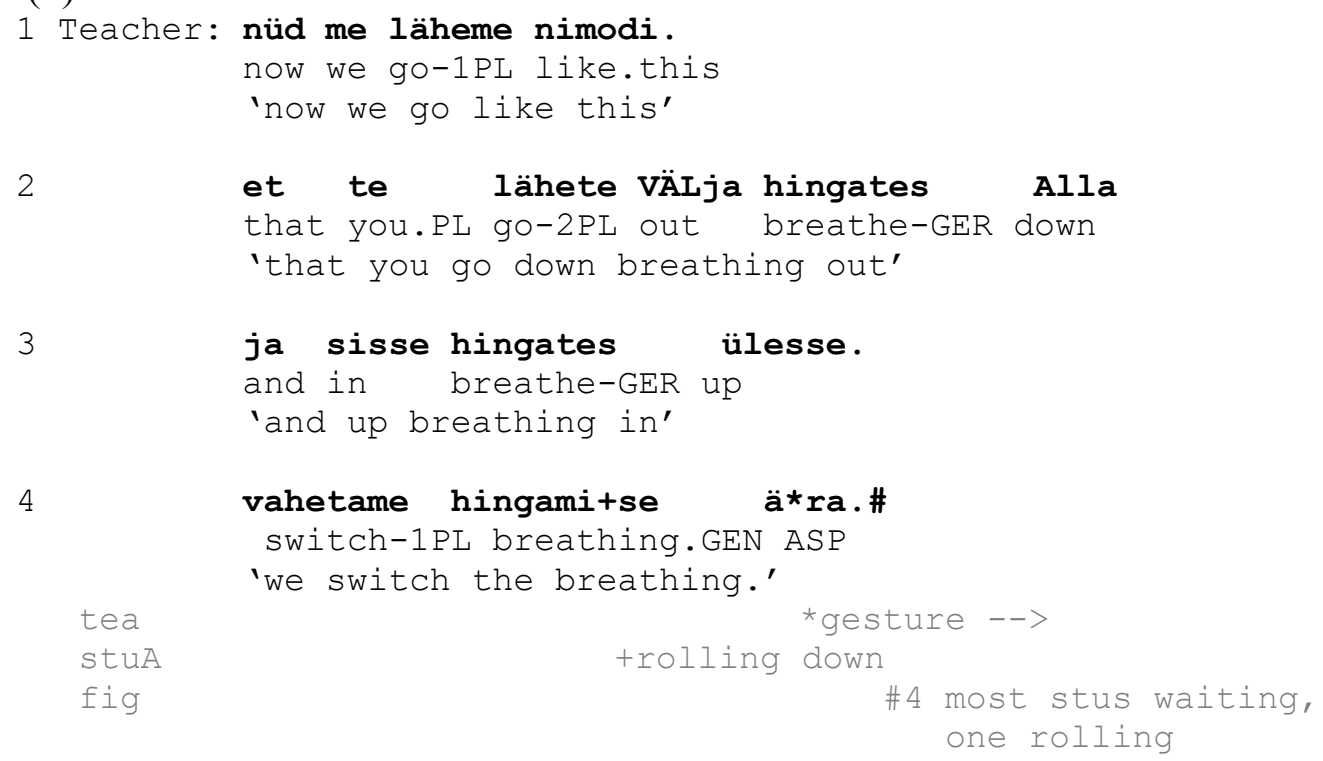

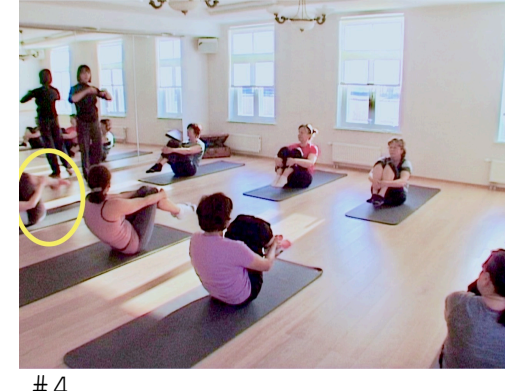
\#4

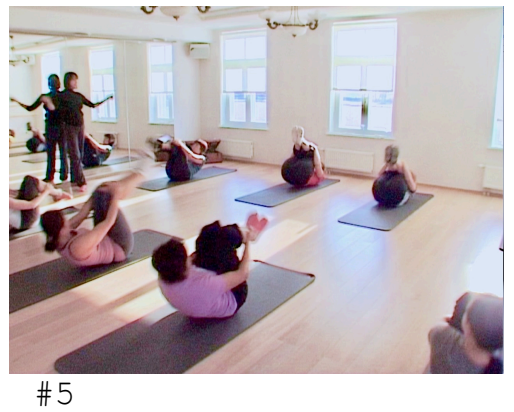

\# 5

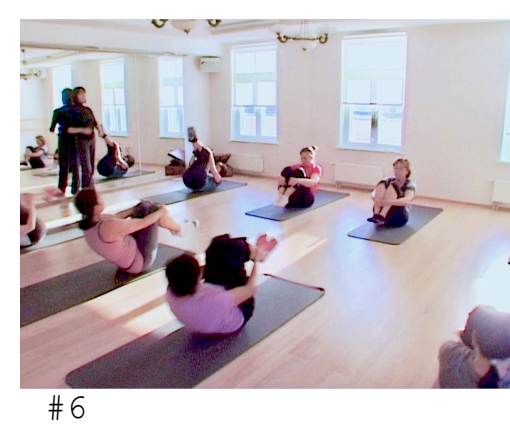

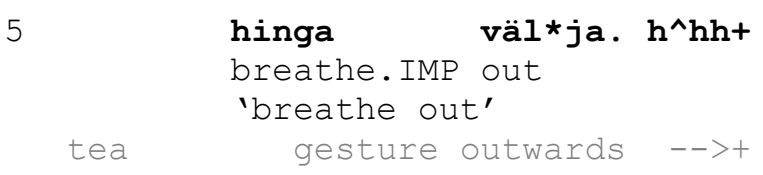
5

\begin{abstract}
${ }^{2}$ Note that the Estonian verb hinga- 'breathe-' can be uttered with our without the initial velar fricative.
\end{abstract}




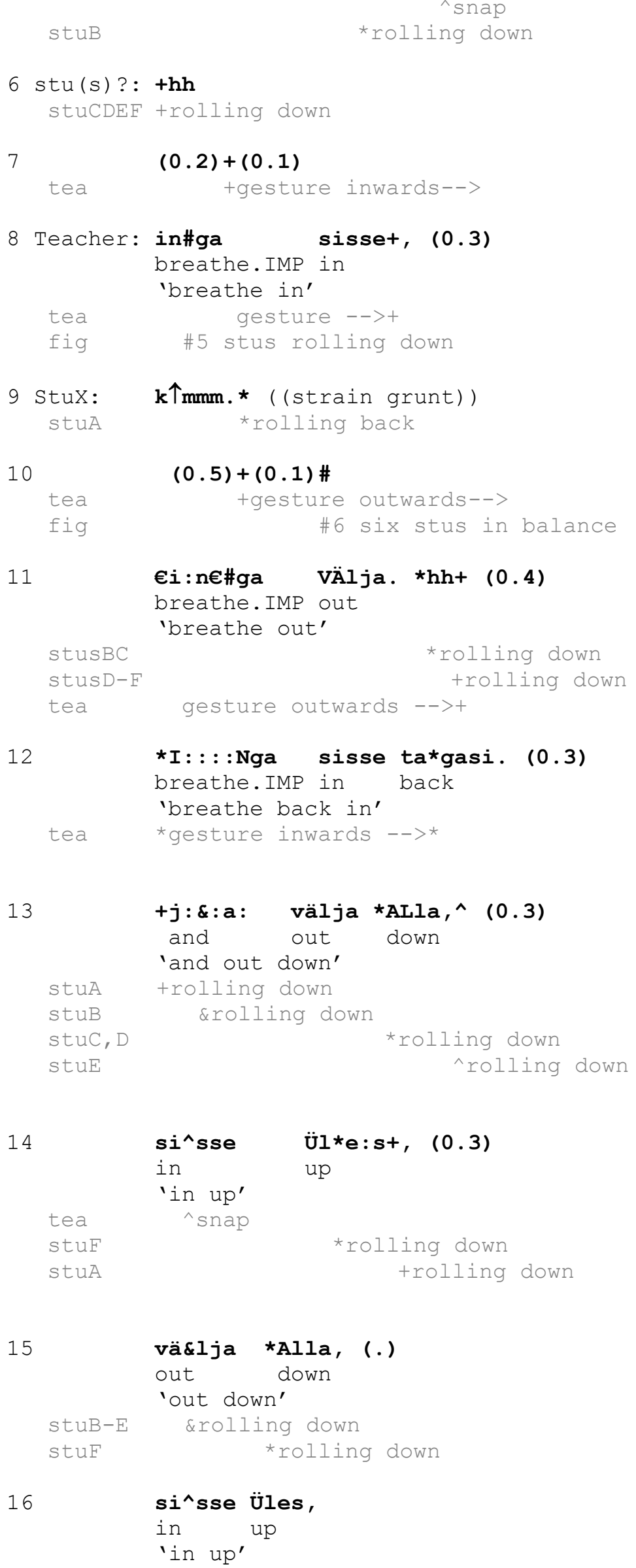


Let us look at the launching of the formulas hinga välja, hinga sisse 'breathe out, breathe in', välja alla, sisse üles 'out down, in up' in this excerpt. Lines (1-4) represent the teacher's relatively explicit instruction to breathe during the exercise. It consists of one clause with a projective manner adverb nimodi 'like this' (line 1, Keevallik 2011), one grammatically subordinated clause (line 2) with a coordinated element (line 3), and another full clause (line 4). This is all uttered before the actual exercise begins. In the aftermath of the expanded instruction, the first separate imperative phrase hinga välja 'breathe out' in line (5) emerges as a directive which makes relevant immediate compliance. As the students have been waiting in start position, the phrase directs them to perform the first segment of the exercise. It is recognizably a reduced version of what was just instructed extensively in lines (1-4), addressed to the students through the second person imperative. Furthermore, it is accompanied by an informative outward gesture which iconically represents the backward movement in the exercise, while the phrase is followed by a hearable outbreath, a demonstration of one aspect of the rolldown.

The students hear and see line (5) as a directive to be immediately complied with. A second student starts rolling back on välja 'out'. The rest follow after the teacher's demonstration of an outbreath $h h h$. The phrase inga välja 'breathe out' has thus emerged as a prompt for the first segment of the exercise, that of rolling back on an outbreath. By structurally and temporally building on the initial explanation, it has come to index something much more complex than what it expresses lexically. The ensuing pause of 0.3 seconds (line 6) seems to be designed to wait for the students to arrive at the ultimate rolldown position (as shown in Figure \#5).

After most of the students have rolled far back on their spines, the teacher begins to gesture inwards and produces a parallel imperative construction inga sisse 'breathe in' (line 8). With that she has launched a rhythmic practice of an exercise, consisting of two segments, rolling down and up. The concise linguistic instructions function as formulas for what is to be done immediately. The vocalization $\mathrm{kmmm}$ in line (9), most probably by one of the students, makes hearable the necessary effort in the abdomen to bring the body up. During the pause after it, six students roll to seated position, as shown in Figure \#6. By repeating the exact same formula as at the beginning, inga välja 'breathe out' in line (11), the teacher indexes a repetition of the same exercise, and by now her utterances basically only serve to provide the timing for it and thereby synchronize the entire class. The next segment of the exercise, as well as the formula inga sisse 'breathe in' can already be predicted. The lengthening of the initial vowels in both of these formulas in lines (11-12) serve to wait for the students' actual movement, so that they can comply with the instruction promptly after its completion (see the multimodal transcript in line 11) and thus be on time. In addition, the teacher does a display of effort on the initial syllable in- of line (11). She utters it with a constrained glottis, as a solidary acknowledgement of others' current effort (see Keevallik (2015:317-318) for similar uses of vocalizations in a dance class). She is thus joining in with her students' bodily struggle by means of a creaky voice. With the help of words, 
pausing, stretching, and voice quality, she is vocally reflecting as well as guiding what the others' bodies do in the class. By a series of repetitive concise utterances with only the words sisse 'in' and välja 'out' switched in lines (512), the teacher manages a coherent rhythm for the exercise which is repeated twice during this period.

In lines (13-14) the formula changes into an even more concise format välja alla, sisse üles 'out down, in up'. While in the first two rounds of the exercise, the adverbs välja 'out' and sisse 'in' were combined with an imperative, thus resulting in classical verb phrases, in the last two rounds they are combined with another set of adverbs, alla 'down' and üles 'up', which does not result in a recognizable grammatical phrase. Nevertheless, the ad hoc verbal formulas, in this case Adverb + Adverb, make perfect sense for the participants at the precise temporal junctures in this activity context, which is evidenced in the students' continuing practice. Also, these formulas build indexically on the initial description of the exercise in lines (1-4), and they likewise reflect as well as guide the emergence of further rounds. Most students start rolling down during the formula välja alla 'out down' while two are late, as shown in line (14) of the transcript, and one of them catches up by line (15). We are thus witnessing a minute temporal coordination between the directive and the compliance, with a few students rolling down during the formula and others after it. In any case, the teacher-established rhythm is the same for everyone. The rhythm is further enhanced by a finger snap on the first syllable of the formula in lines $(5), 14$ ) and (16). Throughout the exercise rounds, the teacher does not only impose the rhythm, but also tunes in to the students' body inertia, especially in lines (11-13) where initial vowels are lengthened, and during the pauses, where she waits for the bodies to arrive in the position for the next move.

The formulas are deployed repetitively and rhythmically, fitted to the students' moving bodies and indexing the movement in real time. Repetition thus seems to be both synchronizing the others' repetitive movements and occasioned by them. The words välja 'out' and sisse 'in', which index the central matter of breathing, are repeated altogether four times in various combinations. These are reduced versions of the initial instruction, used for marking the temporal structure, and prompt or accompany the different segments of the exercise as well as inform the students of the number of rounds. Partially similar reduction in the complexity of verbal instruction across a series of tries has been described by Broth et al. (2017) for starting a car and by Deppermann (2018) for parking a car, but in the current case the timeframe seems to be much shorter. Crucially, verbal structure here emerges across participants and modalities in a fine attunement to the students' bodies rolling down and up.

Another characteristic of the formulas is that they are often prefaced by $j a$ 'and', as can be seen in line (13) above. $J a$ seems to be a suitable device for creating and maintaining rhythm. Among other things, it is easy to lengthen because of its open syllable structure, which we also saw in the above example. In the formulas it is placed initially, as a preface. The next excerpt (3) illustrates the use of $j a$ 'and'-prefacing as well as the interchangeable use of formulas and counting. The excerpt starts when the exercise is already in 
progress and the teacher utters the correction or reminder sirutage kaugusesse 'stretch into the distance' in line (1). The utterance maintains the ongoing rhythm of the exercise with the help of prosody - the first half is produced rapidly and the apex of the leg stretch (shown in Figure 7) is marked with stress on the first syllable of kAugusesse 'into the distance'. The repetitive formula which starts in line (2) merely contains the initial conjunction ja 'and', and one adverb välja 'out'. After four repeats, the formula is transformed into consecutive numbers which also serve to count down to the end of the exercise.

(3)
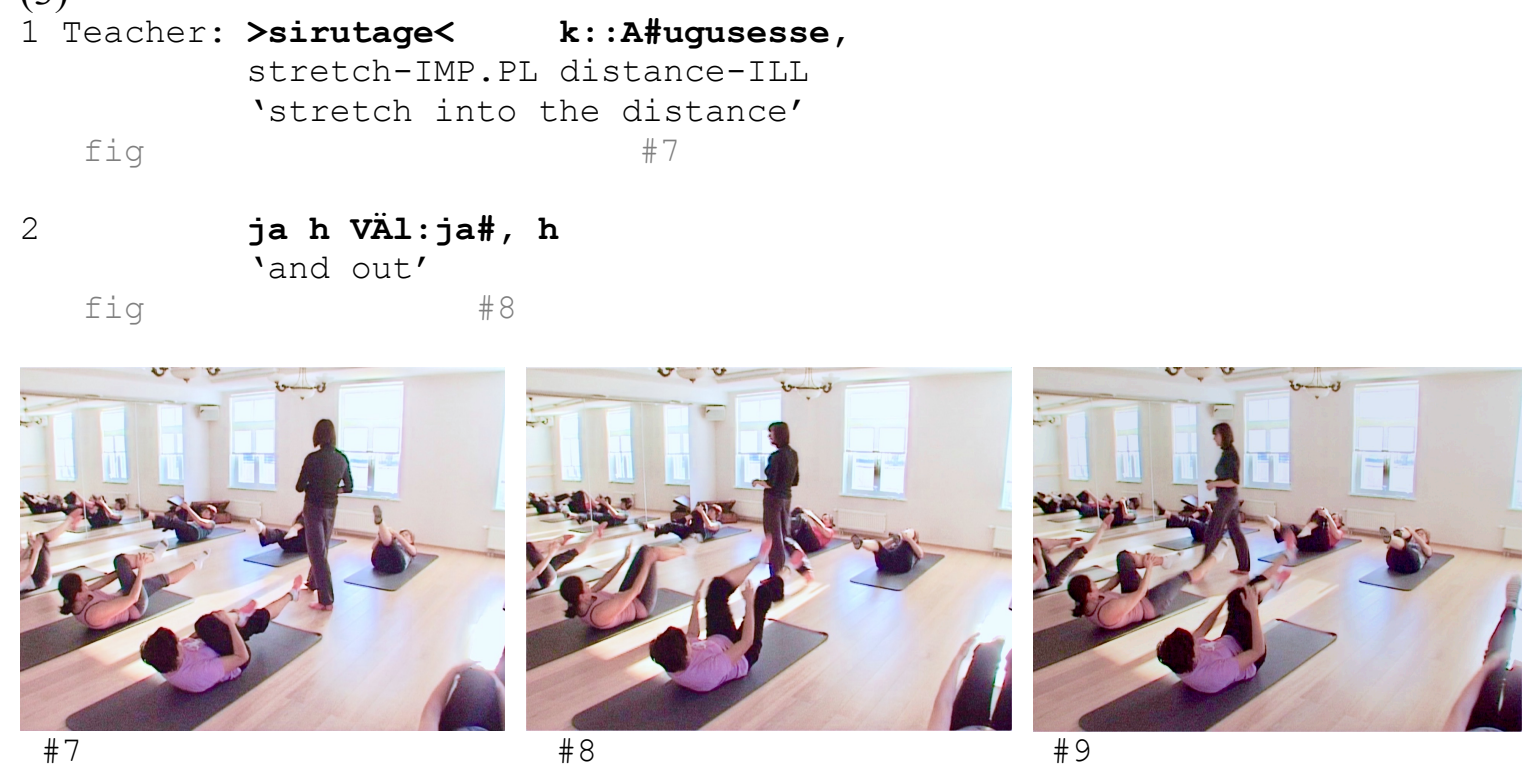

ja: v̈̈^l:\#ja, (.)

'and out'

tea

fig

$\wedge_{\text {snap }}$

4

.ja: vä^lja, (.) ((ingressive airflow on ja))

'and out'

tea

^snap

5

ja: vëlja, (.)

'and out'

6

JA: : : neli, (0.2)

'and

four'

$\begin{array}{ll}\text { JA : : } & \text { kol }: m,(.) \\ \text { and } & \text { three' }\end{array}$




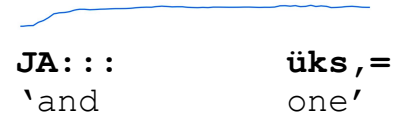

Let us start by looking at the first four rounds of the exercise. When correcting the students' current performance in line (1), the teacher effectively picks the rhythm for her vocal production from the simultaneously moving students' bodies. The lengthening on $k$ functions as a wait for at least the two students in front of her (in the far left corner) to arrive at the apex of their movement, so that she herself can utter the stressed syllable K::A in synchrony with the extreme extension of their move (see Figure 7). This is an achieved synchrony between the speech of the teacher and the legs of the students. Likewise, the lengthening on $j a$ 'and' and the short pause after it in line (2) reflect her waiting for the students so that there is synchronization of the talk and the bodies. Figure 8 illustrates how the students simultaneously withdraw from the extension by the end of the word välja 'out', while figure 9 shows another extension precisely on the stressed first syllable on the same word in line (3). The teacher does not gesticulate in this excerpt but she snaps in lines $(3,4)$, which further enhances the rhythm in the auditory space, while the students embody it. The directive formula ja välja 'and out' emerges as synchronous with the compliance. The syllable väl- is designed to fall on the extreme leg stretch, thus rendering the $j a$ 'and' as if indexing the current movement toward the extreme position, a preparation for it. The pauses are a further strategy to create near synchrony, as they constitute a wait for the legs moving back to the starting position. Both the conjunction and the pause are instrumental for synchronization.

The $j a$ 'and'-preface adds another syllable to each formula (as in ja välja 'and out' vs. simply välja 'out') and thus, first of all, guarantees the flow of speech throughout the exercise. It also effectively marks the routine succession of consecutive segments within the exercise. Along similar lines, Heritage and Sorjonen (1994) argued that English and-prefaced questions in medical interaction were agenda and routine based, rather than contingent on locally emerging matters. A pitch reset on every $j a$ 'and'-preface in the above excerpt also suggests that every utterance represents a next event, as has been discussed for English and by Barth-Weingarten and Couper-Kuhlen (2011). In the Pilates class, the utterances are furthermore timed with each consecutive physical move in progress, thus indexically tied to consecutive events in real time. After four repetitions of the formula ja välja 'and out', the teacher marks a boundary by raising her voice on JA 'and' (line 6) and switches to numbers. From now on, the stresses are on the conjunction, which illustrates the possibility of prosodic variation within these short words. Crucially, distinct repetitive pitch movements occur on $j a$ 'and' in lines (6-8), further underlining 
the parallelism in movement. Still, the apex of the leg stretch continues to fall on the other half of the formula, the numerals.

Numbers are of central organizational importance in exercising activities. If the count does not start from 'one', it constitutes a countdown that informs the participants of the time still remaining till the end of the exercise, that is, how many repetitions are yet to be accomplished. As can be seen in line (19), immediately after 'one' the teacher guides a transition to the next exercise. Numbers in countdowns are not in themselves repetitions but participate in the repetitive structures, and they have a projective capacity, as does the prosody. Interestingly, as was also the case in excerpt (2), the repetitive formulas seem to emerge in sets of four, which have a nice internal rhythmic potential (as shown in the pitch curves provided for lines 6-9). At the same time, this also reflects the logic of many exercises consisting of two symmetrical segments, such as going down and up (as in excerpt 2), or switching two legs (as in excerpt 3 ). This again contributes to the relatively high projectability of the next move within a launched exercise. In the current excerpt, the teacher employs all these structuring devices: rhythm, intonation, numbers, and formulas. With the help of her voice she seemingly joins in the embodied practice, in particular when picking up the rhythm from the exercising students, and guides it all the way to its end.

The repetitive formula may, however, include a broader variety of linguistic items. Excerpt (4) shows somewhat longer repetitive formulas which involve imperatives and (adverbial) phrases. In this case, the teacher is demonstrating the exercise throughout the segment: she is lying on her back with her legs up and her hands drawing circles. In lines (1-2) she does exactly the preparatory moves that she describes. She puts her hands on her lower legs and holds up her shoulders with the abdomen. That this is a strenuous position is reflected in her tense voice on the word peale 'onto', which may either reflect her own bodily struggle or be a deliberately performed display of necessary effort for the benefit of the students. She then goes on to show how to stretch out the legs and arms, while providing the exercise label kahe jala sirutus 'two-leg stretch' and the vocalization $u h h h$ (lines 2-3). The latter also constitutes an indexical embodied display of the teacher's own bodily effort. The verbally relatively complex formula is established in lines (4-5).

(4)

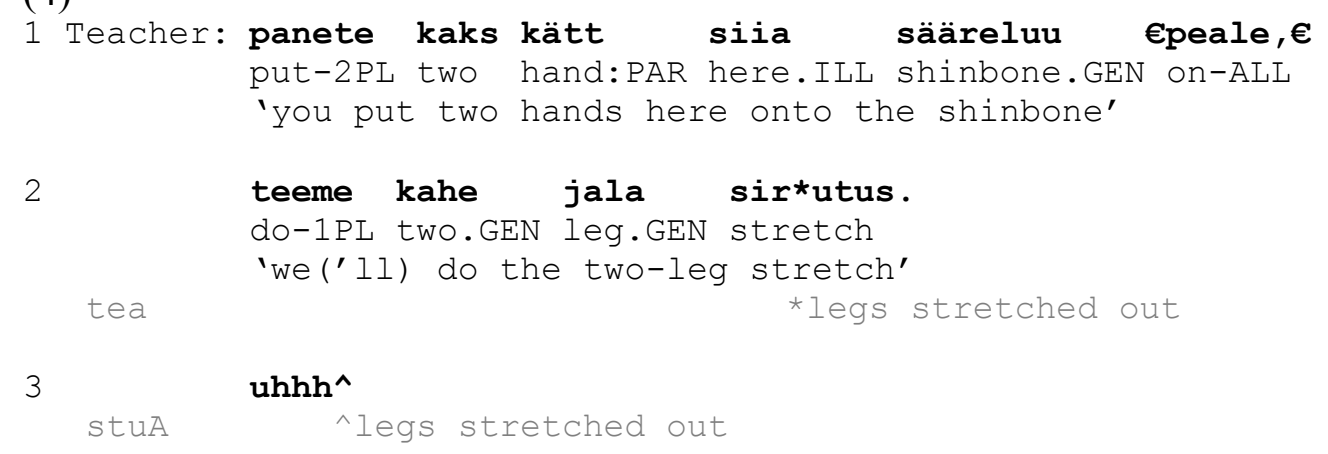




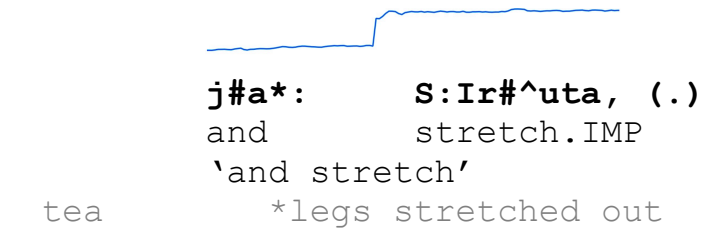

stuA-G

fig

^legs stretched out
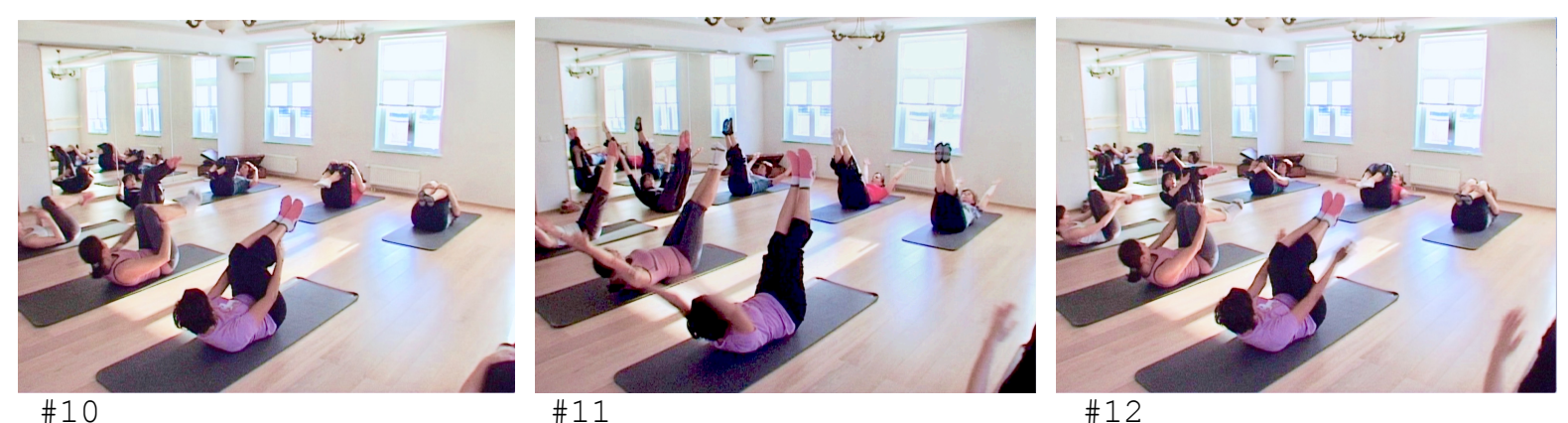

\#11

\#12 'and circling together'

stuA-G

fig

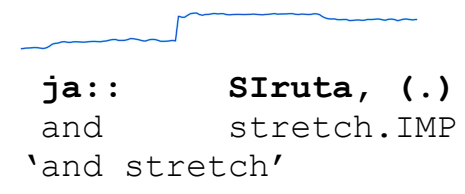

\section{ja:: J:Uurde}

and together.ILL

'and together' 

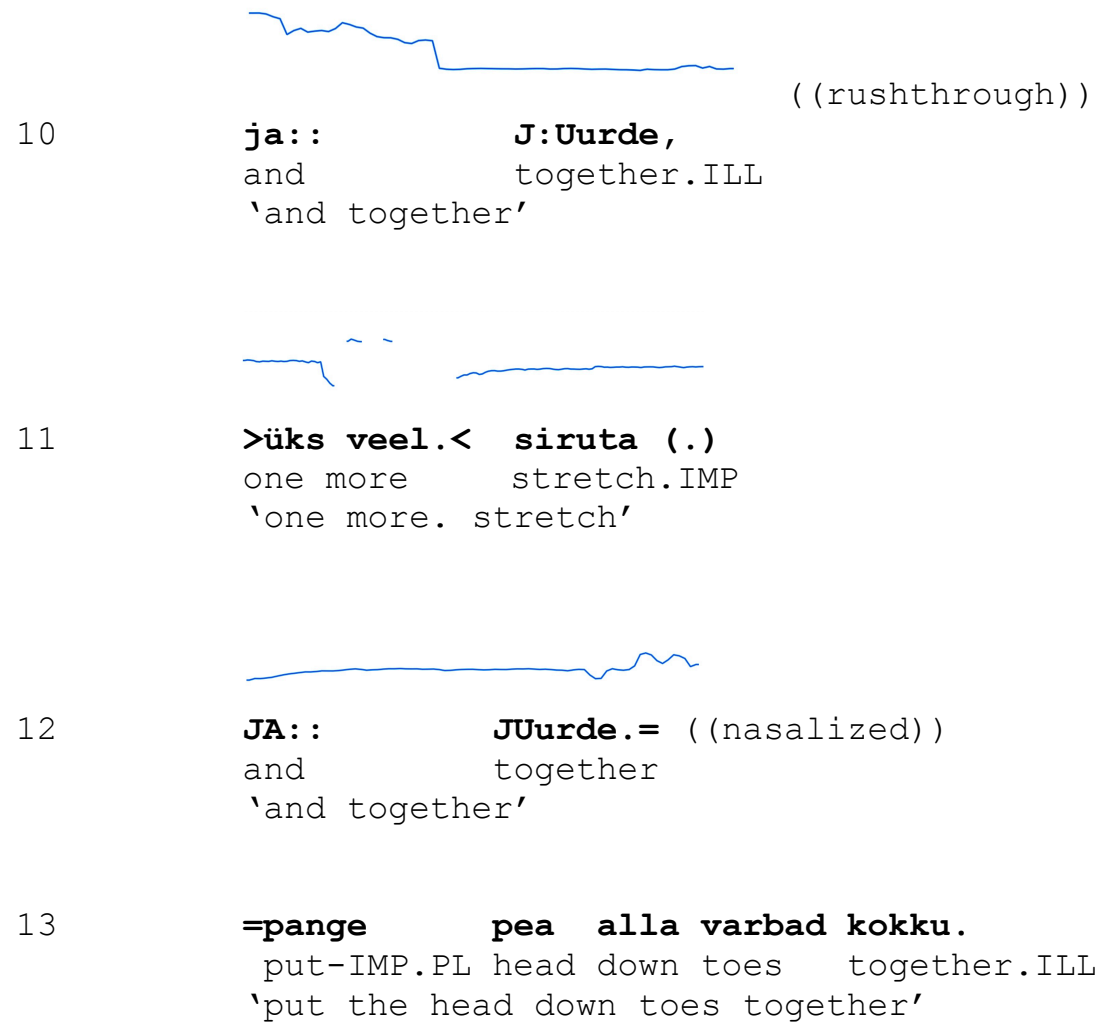

One student already manages to do the stretch together with the teacher in lines (2-3), while the rest of the students wait for the second round that starts on line (5), as shown in Figure 10. The teacher stretches out her legs slightly ahead of everybody else, but exactly on her stressed syllable $s i$ - the whole class is simultaneously in the stretched position (see Figure 11). Whether following the teacher's voice, her body, or fellow students' bodies, all the students are now in synchrony with the vocal production. The latter emerges as a directive for immediate compliance as well as a description of the ongoing bodily action. After the exercise has been demonstrated and the rhythm established by the teacher, the formula essentially functions as a synchronization device. Consider for example the joint return to start position in Figure 12 above. The exercise continues in near synchrony until line (12), with the teacher continuing to launch next moves slightly ahead of the students. Her vocal production ends up perfectly fitted to the students' complying movements. It is rhythmical and designed for achieving multiple rounds of a single exercise.

As to the formula, it is somewhat more complex than in the previous excerpt, involving not only an imperative siruta 'stretch' (lines 5,7,9,11) but also an adverbial phrase ringiga juurde, lit. 'with circle together' (line 6). The latter describes the crucial hand movement in the exercise. Like excerpt (2) above, the current excerpt features a double formula for the two segments of the exercise, perhaps occasioned by the somewhat longer temporal segments in this exercise, as opposed to, for example, the exercise which was presented in excerpt (3). The formulas are $j a$ 'and'-prefaced, but also feature another less 
frequent preface jälle 'again' (line 9). Furthermore, we can see here how the formulas tend to become increasingly shorter over time, as the word ringiga 'circling' does not appear in the final repetitions. This apparently results in the lengthening of the initial sound of $j$ :uurde 'together' or JA: 'and' $(8,10,12)$, although the exercise itself does not become slower. Typically, also, in order to keep her breath and the rhythm, the teacher has to produce some parts of the pattern with ingressive airflow (line 9).

As to the crucial participant concern in a Pilates class - how many more repetitions have to be performed - we can in the current case see a different solution, namely announcing the last instance with üks veel 'one more' (in line 11). In addition, there are specific recurrent prosodies which can signal the penultimate and the final repetition of an exercise. In the current case the penultimate repetition (lines 9) is introduced with level pitch, in contrast to a step-up on the word siruta 'stretch' in previous instances (lines 5,7). In line (10) the pitch on juurde 'together' rises remarkably, in a sharp contrast to the previous lowering of pitch on the same word (lines 4,6,8). This seems to be a recognizable prosodic pattern for penultimate exercise rounds in Estonian. Likewise, the very final round (lines 11-12) features level pitch, which is hardly terminated before the teacher continues into instructing a transition to the next exercise. All of this sets the penultimate and last round of the exercise apart from the first two rounds. In the current excerpt, the very last formula (line 12) is furthermore nasalized, marking it as distinct from the prior segments. The prosody and voice quality thus both work for projection and completion of several rounds of an exercise, informing the students as well as reflecting their simultaneous movement. They also render the talk as a songlike whole, a vocal accompaniment to the entire exercise.

We have now seen how the linguistic practice of repetition works to instruct repetitive rounds of a physical exercise, with locally established formulas built on initial instructions and demonstrations, uttered with appropriate rhythms and conventionalized melodies by the teacher. The formulas may be more or less complex grammatically and involve prefaces such as $j a$ 'an' and jälle 'again'. We will continue to explore a prosodically different repetition format used for accomplishing another physical task, which among other things shows that the above formula repetition pattern is robust and distinct.

The second type of extensive repetition which occurs in this activity context is likewise used for synchronization of the Pilates students, but not for repetitive moves. Instead, it instructs an extended bodily effort and is thus quite differently organized. In excerpt (5) the students are supposed to come up and balance on their buttocks, as instructed by the teacher in lines (1-2). She then produces a prosodically fused repetition of the imperative püsige 'stay there/hold it' (lines 3-4), urging the students to stay in a strenuous position. Her voice is low and soft, not rhythmic as in previous examples, and the different repetitions flow into each other forming a single continuous pitch contour (see the Praat picture in lines 3-4) which is easily extendable, if needed.

Furthermore, the imperative is not reused from the original instruction, as was the case with the formula above, but rather features a semantic shift from jääge ülesse 'stay up, stop rolling' to püsige, approx. 'stay there, hold it'. 
(5)

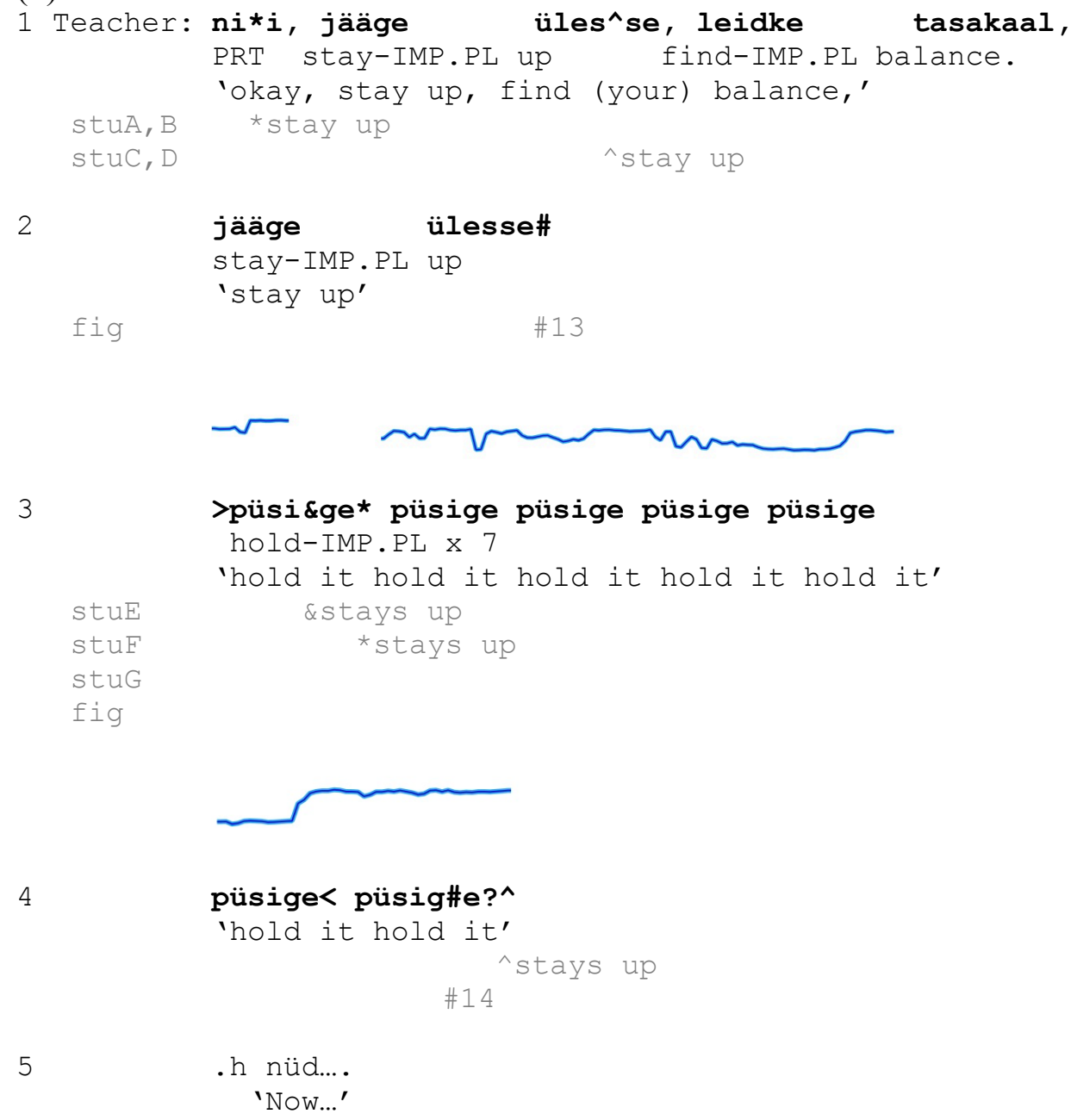

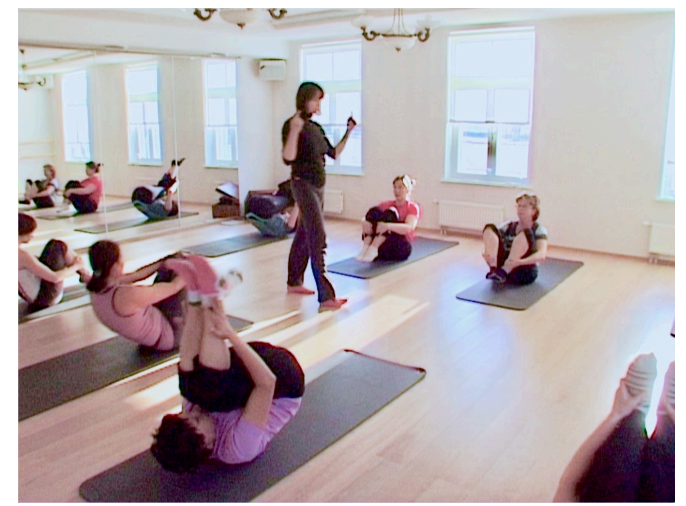

\#13

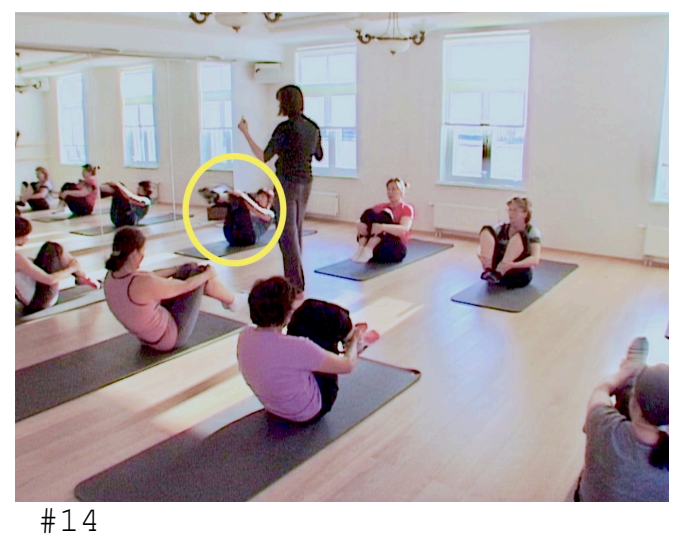

Balancing on the buttocks is the position where the previous exercise ends. The first students stay in this position already on nii, lit. 'so', analyzed as marking a completion of an activity in earlier literature (Keevallik 2010b). The next two students stay in position immediately after the teacher's imperative jääge ülesse 'stay up', and Figure 13 shows the same situation somewhat later. The others follow, one by one, as shown in the transcription, line (3). Interestingly, the the last student only arrives after the last syllable in line (4, see Figure 14). Thus, the teacher may have calibrated the number of repetitions of the 
imperative to match the projected arrival of all the students in the balanced upright position. Her production of the final repetition of the imperative with slower pace, louder voice, and higher pitch may projects the end of the series of repetitions as well as the arrival of the last student in start position for the next exercise. This is yet another way of bringing all the participants in the class into alignment with the verbal instruction as well as with each others' bodies.

In short, this second type of instruction repetition may signal a not-yetachieved quality by everybody in the class, and is thus also minutely tied to the exercising bodies. Each next repetition takes as its impetus the fact that the formulated action or quality is still missing (not all the students are in position), or has to be extended beyond the current moment, held in position. Similar repetitive patterns in guiding an endoscopic camera in surgery have been discussed by Mondada (2014a) as "repairing" camera movements which are treated as still inadequate. Examples include repetition of the imperative zoom and zoom avant 'zoom ahead'. Jefferson (1991:64) argues that when expressing "muchness" the repetition regularly happens thrice, as in working working working. In any case, this kind of repetition is quite different from the formula repetition to accompany students through consecutive rounds of an exercise, where there is no orientation to something problematic which would necessitate correction.

It therefore seems that there are several linguistic-prosodic practices which are used for synchronization in the larger activity contexts of joint physical practice. The achievement of repetitive rounds of an exercise, as was described above, is a distinct practice which deploys specific locally established formulas which may feature grammatical structure beyond single words and word forms, and furthermore involve other rhythmic coordinating devices such as snaps, claps and stomps. The repetitive formulaic synchronization practice builds indexically on the initial instruction. It makes use of the fact that the activity structure and the specific exercise can be anticipated to a certain degree, while the exact number of repetitions has still to be established at each instantiation of the practice. Synchronization is thus both a local and an activity-based achievement with language structure emerging in a locally sensitive manner in a close relationship to the exercising bodies, reflecting situation design. In the last section we will explore this relationship within a single grammatical phrase.

\section{The segment-by-segment emergence of linguistic structure}

Close analysis of grammatical structure as emerging in interaction has revealed how it can be flexibly adapted to local contextual contingencies. Famously, Charles Goodwin (1981) showed how a regular utterance, I gave up smoking cigarettes one week ago today actually, emerged across changing participation frameworks: every next segment of the utterance was tailored to a different recipient, and dependent on whether the recipient was knowing or unknowing about the reported event. The following excerpt (6) illustrates how a single 
phrase by the teacher emerges word-by word and sound-by-sound in response to the evolving body movement of the students.

The teacher is standing and prompting the students on the floor. At least some of the students apparently know the exercise - from a forward bend, they are now supposed to straighten up and then start bending again. Already in response to the teacher's $j a$ 'and' in line (1) they start straightening their spines. Figure 15 shows the students halfway up.

(6)

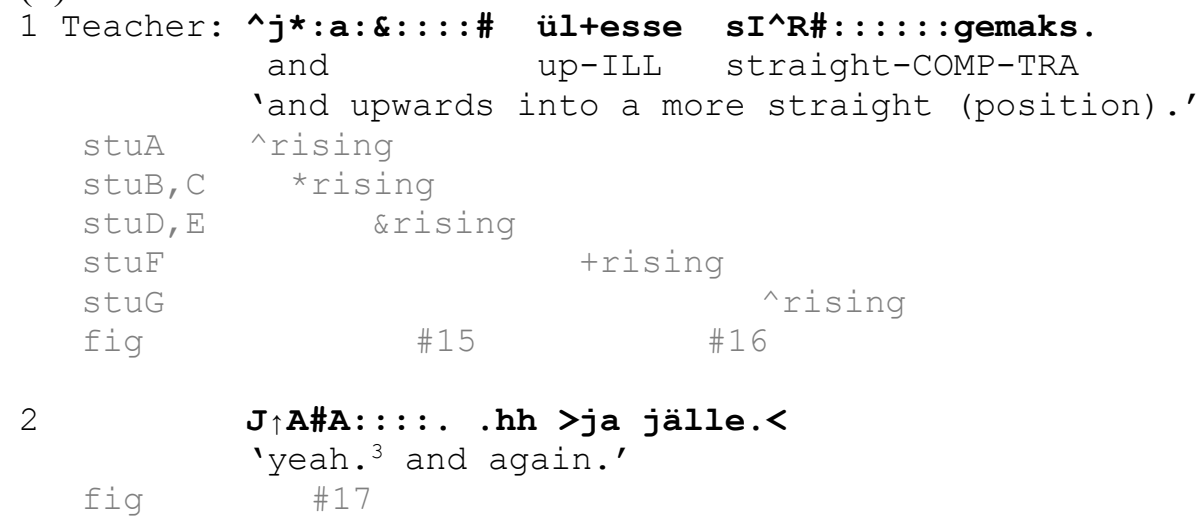

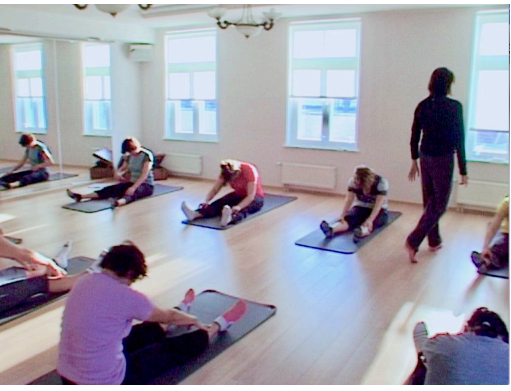

$\# 15$

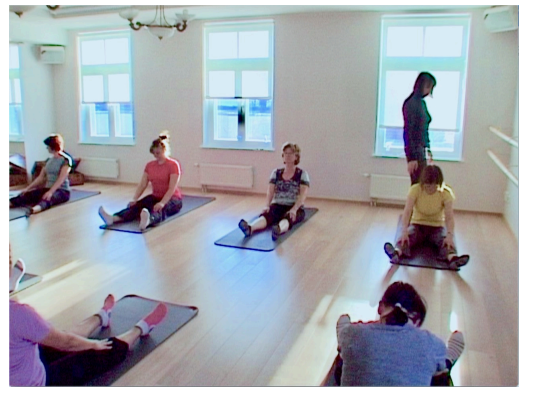

\#16

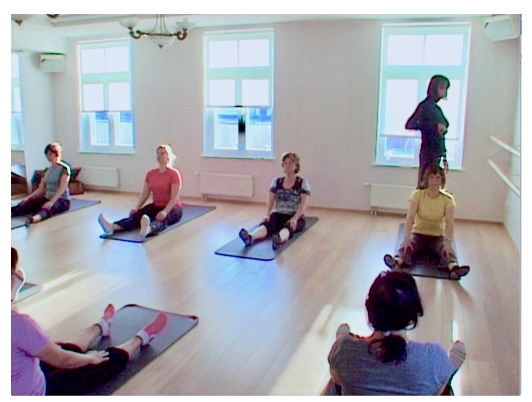

$\# 17$

The teacher utters a grammatical phrase ja ülesse sirgemaks. 'and upwards into a more straight (position).'. These words are well timed with the students' body movements. They direct and provide the timeframe for the straightening. However, since the students are already halfway up on $j a$ 'and', the instructing ülesse 'upwards' emerges partly as a responsive approval of their bodily action, partly as a simultaneous description, and partly as a reminder prompt for the students.

In contrast, the morphologically complex sirgemaks 'become more straight' provides instruction and critique on the simultaneous action, as the students have actually already straightened up by its first syllable (as can be seen in Figure 16), but perhaps with insufficient quality. Studying surgery, Mondada (2014b) discusses similar request-type actions as if "exploiting" the trajectory of the activity and its projectability, occasionally temporally "merging" with it. The grammar of these utterances can reveal systematicity between embodied and verbal behavior at every moment in time. For example, the Estonian

\footnotetext{
${ }^{3}$ The affirmative particle $j a$ has the same basic phonological shape as the conjunction $j a$ but its pragmatics and prosody are different.
} 
morphological ending of Translative $-k s$ in sirge-ma- $k s$ 'straight-more-into' (line 1) is used here in the service of the ongoing concrete movement (guiding its quality), which is typically not in focus in the abstract discussions of mapping meanings to case endings. It is quite plausible that the comparative morpheme $m a$ emerged within the moment, when the teacher had already uttered the lexical root sirge- 'straight', and perhaps found the students' response not quite satisfying during the prolonged $r$. We can see further physical adjustments after it. Embodied responsiveness, as documented in the current study, may provide us with evidence on how participants understand the various structures, so that we as analysts do not have to just assume that we all share the same knowledge about them. Crucially, the grammatical combination of a conjunction, the illative and the translative form are here a coincidental result of the students' bodies moving and being at the same time instructed about the exercise. Linguistic structure, even though thoroughly "grammatical", emerges here not as an application of some cognitive process but in the interplay with others' exercising bodies and the routine organization of the Pilates class.

One of the affordances of the strategy is that students can "chime in" at various moments in time: some (perhaps more experienced in the class) can project the next movement and start moving on the projective $j a$ 'and', while others may have to wait for more of the directive in order to know what to do (see the embodied transcript of line 1). This kind of synchronous talk thus caters to the different needs in the class, and achieves an essentially coordinated practice, reflecting the pedagogical activity context in a different way. The teacher also uses iconic prosody which falls on bends and rises on bodily rises. Words and sounds are lengthened in order to achieve progress in the exercise as well as to iconically represent the appropriate length of a move. Furthermore, a specific vocal production by the teacher, such as an extreme lengthening of a sound (e.g., $r:::, a:: *$ ) may convey the expected effort by the students. The prosodically extreme $J \uparrow A A: \because:$ ' 'yeah' in line (2) above appreciatively responds to the students' straightening spines and at the same time encourages them to extend and enhance their efforts, providing a time-frame for the appropriate performance - till the end of the $J \uparrow A A: \ldots$ ' 'yeah'. The $J \uparrow A A: \cdots$ has thus accomplished a lengthy and specific response in the students' bodies while the move is still underway. This illustrates the achievement of verbal and bodily synchrony as distributed across different participants.

In the last section of the chapter we have thus seen how instruction and compliance emerge in near-synchrony during the phrase ja ülesse sirgemaks 'and upwards into a more straight (position)' (line 1), and the distinction between directiveness and a responsiveness gets similarly blurred in the response cry $J \uparrow A A: \cdots:$ (line 2). Linguistic structure in the teacher's talk is designed to merge with the bodily actions by the students which are simultaneously guided and corrected through it. Interpersonal synchrony between the moving bodies and teacher talk, mutually reflexive of intersubjective understanding, is here achieved across different modalities during a single grammatical phrase. 


\section{Conclusion}

The above study has shown how a variety of linguistic structures (repetitions, formula, countdowns, adverbial phrases) can be deployed to achieve synchrony between teacher talk and the students' body movements in a physical training context. The teacher's vocal practices are quite literally designed to mobilize the bodies of the Pilates students in the here and now; they guarantee progress through the different exercises and their repetitions. At the same time, emergent grammar is reflexively shaped by these very body movements. Syntactic structures usefully described by linguists (imperative, adverb, phrase) can be occasioned by, and coordinated with, an (other's) embodied action; the emerging lexicon as well as repetitive formulas are fitted to local activity trajectories, they are situation designed. While some verbal devices, such as counting, are relatively conventionalized in physical training activities, other devices, such as formula repetition, reveal considerable variation in structure.

Likewise, the temporality and spatiality of the embodied action may be consequential for the choice of grammar. Especially as a counterbalance to the idea that language structure results from abstract cognitive principles, we should entertain the possibility that it emerges stepwise, incrementally, as a series of local solutions to participants' current actions and has specific features in different activity settings. In getting a student to perform a Pilates exercise, the teacher makes use of the segmental and successive nature of grammar as well as the iconic capacity of her own body, including the affordances of voice effects such as extreme lengthening and prosody, rhythmic production of structures, and large tonal modulations. Verbal structure by a single speaker is produced in response to the others' body movements, as well as timed with them in order to guide current or incipient performances, displaying vocally how the students need to mobilize their bodies at successive moments in the class. In short, it was shown that besides lexicon and grammar, prosody is a resource for mobilizing others' bodies.

The chapter has argued that teacher instructions can be designed to emerge in synchrony with the students' practicing bodies, thus both instructing and reacting, initiating and responding. While the students can indeed be documented to comply with teacher instructions after their production, at other times the teacher selects the rhythm and pace for her "instructive" talk from the moving bodies of the students. So far most interactional studies have focused on directives and instructions that have to be complied with successively (Cekaite 2010; Drew and Couper-Kuhlen 2014; see, however, Broth and Keevallik 2014 on the early response orientation in dance instruction). In contrast, the current chapter showed that directives can also be designed for synchronous compliance. This is possible due to at least partial recognizability of the exercises for the Pilates students and, likewise, partial projectability of next moves in this activity context. In contrast to many other activities, entitlement by the teacher to guide the students and provide the pace for the class is not negotiated, and is, in fact, only challenged jokingly by the participants who claim to be exhausted. The teacher can also set the pace for every exercise, as there are no external concerns regarding time (such as in surgery or racing). In any case, this particular setting shows that the mutual 
temporalities of verbal and embodied trajectories are complex and do not necessarily become organized in what could be seen as traditional conversational sequences. A speaker can mobilize others to act - in fact, to make a significant physical effort - while still uttering the instruction.

\section{Transcription conventions}

$\begin{array}{ll}\text { underlining } & \text { - stress } \\ \text { CAPS } & - \text { emphasis } \\ {[\text { [ ] }} & - \text { overlaps } \\ = & - \text { latching of units } \\ (0.5) & - \text { pause length in tenths of a second } \\ (.) & - \text { micropause } \\ \text { h } & - \text { breathing out } \\ . \text { h } & - \text { breathing in } \\ . \text { ja } & - \text { talk produced with ingressive airflow } \\ ((\text { comment })) & - \text { transcriber's comment } \\ : & - \text { lengthening of a sound, } 0.1 \text { sec } \\ . & - \text { pitch fall at the end of an intonation unit } \\ ? & - \text { pitch rise at the end of an intonation unit } \\ , & - \text { level pitch at the end of an intonation unit } \\ <\text { slower }> & - \text { slower speech } \\ >\text { faster }< & - \text { faster speech } \\ 0 & - \text { sotto voce } \\ € & - \text { strained voice } \\ \uparrow & - \text { distinct pitch movement upwards } \\ *+\& \wedge & - \text { alignment of body moves }\end{array}$

\section{Glossing conventions}

$\begin{array}{ll}\text { ALL } & - \text { allative } \\ \text { ASP } & - \text { aspect } \\ \text { COMP } & - \text { comparative } \\ \text { GEN } & - \text { genitive } \\ \text { GER } & - \text { gerund } \\ \text { ELT } & - \text { elative } \\ \text { ILL } & - \text { illative } \\ \text { IMP } & - \text { imperative } \\ \text { IMS } & - \text { impersonal } \\ \text { KOM } & - \text { komitative } \\ \text { NEG } & - \text { negation } \\ \text { PAR } & - \text { particle } \\ \text { PL } & - \text { plural } \\ \text { PPT } & - \text { participle } \\ \text { PRT } & - \text { particle } \\ \text { TER } & - \text { terminative } \\ \text { TRA } & - \text { translative } \\ 1,2,3 & - \text { person }\end{array}$




\section{References}

Barth-Weingarten, Dagmar, and Elizabeth Couper-Kuhlen. 2011. "Action, prosody and emergent constructions: The case of 'and'." In Constructions: Emerging and Emergent, ed. by P. Auer, S. Pfänder, 264-293. Berlin: De Gruyter Mouton.

Betz, Emma, Carmen Taleghani-Nikazm, Veronica Drake, and Andrea Golato. 2013. Third-position repeats in German: The case of repair- and request-for-information sequences. Gesprächsforshung 14: 133166.

Bolden, Galina. 2009. "Beyond answering: Repeat-prefaced responses in conversation." Communication Monographs, 76(2), 121-143.

Broth, Mathias, Jakob Cromdal, and Lena Levin. 2017. "Starting out as a driver: Progression in instructed pedal work." In Memory Practices and Learning: Interactional, institutional and sociocultural perspectives, ed. by Å. Mäkitalo, P. Linell, R. Säljö, 115-152. Charlotte, N.C.: Information Age Publishing.

Broth, Mathias, and Leelo Keevallik. 2014. "Getting ready to move as a couple. Accomplishing mobile formations in a dance class." Space and Culture 17(2): 107-121. 10.1177/1206331213508483

Bybee, Joan. 2003. "Cognitive processes in grammaticalization." In The New Psychology of Language, Vol. II, ed. by M. Tomasello, 145-167. Mahwah: Erlbaum.

Cekaite, Asta. 2010. "Shepherding the child: embodied directive sequences in parent-child interactions." Text and Talk 30(1): 1-25. https://doi.org/10.1515/text.2010.001

Clift, Rebecca. 2016. Conversation Analysis. Cambridge: Cambridge University Press.

Couper-Kuhlen, Elizabeth, and Margret Selting. 2018. Interactional Linguistics: Studying language in social interaction. Cambridge: Cambridge University Press.

Curl, Traci S., John Local, and Gareth Walker. 2006. "Repetition and the prosody-pragmatics interface." Journal of Pragmatics 38(10): $1721-1751$.

Deppermann, Arnulf. 2018. Changes in turn-design over interactional histories - the case of instruction in driving school lessons. In Time in Embodied Interaction: Synchronicity and sequentiality of multimodal resources, ed. by A. Deppermann, J. Streeck, 293324. Amsterdam/Philadelphia: John Benjamins.

De Stefani, Elwys, and Anne-Danièle Gazin. 2014. "Instructional sequences in driving lessons: Mobile participants and the temporal and sequential organization of actions." Journal of Pragmatics 65: 63-79. doi:10.1016/j.pragma.2013.08.020

Drew, Paul, and Elizabeth Couper-Kuhlen (eds.). 2014. Requesting in Social Interaction. Amsterdam/Philadelphia: John Benjamins.

Goodwin, Charles. 1981. Conversational Organization: Interaction between speakers and hearers. New York, NY: Academic Press.

Heritage, John, and Marja-Leena Sorjonen. 1994. "Constituting and 
maintaining activities across sequences: And-prefacing as a feature of question design." Language in Society 23(1): 1-29.

Hopper, Paul. 1998. "Emergent grammar." In The New Psychology of Language: Cognitive and functional approaches to language structure., ed. by M. Tomasello, 155-175. Mahwah, NJ: Lawrence Erlbaum.

Jefferson, Gail. 1991. "List construction as a task and resource." In Interactional competence, ed. by G. Psathas, 63-92. New York, NY: Irvington Publishers.

Keevallik, Leelo. 2010a. "Social action of syntactic reduplication." Journal of Pragmatics 42(3): 800-824.

Keevallik, Leelo. 2010b. "Marking boundaries between activities: The particle nii in Estonian. Research on Language and Social Interaction 43(2): $157-182$.

Keevallik, Leelo. 2011. "Pro-forms as projective devices in interaction." Discourse Processes 48(6): 404-431.

Keevallik, Leelo. 2012. "Compromising progressivity: 'no'-prefacing in Estonian." Pragmatics 22(1): 119-146. 10.1075/prag.22.1.05kee

Keevallik, Leelo. 2015. "Coordinating the temporalities of talk and dance." In Temporality in Interaction, ed. by A. Deppermann, S. Günthner, 309-336. Amsterdam/Philadelphia: John Benjamins.

Linell, Per. 2009. Rethinking Language, Mind, and World Dialogically: Interactional and contextual theories of human sense-making. Charlotte, NC: Information Age Publishing.

Mondada, Lorenza. 2014a. "The surgeon as a camera director: maneuvering video in the operating theatre." In Video at Work, ed. by M. Broth, E. Laurier, L. Mondada, 97-132. London: Routledge.

Mondada, Lorenza. 2014b. "Requesting immediate action in the surgical operating room: Time, embodied resources and praxeological embeddedness." In Requesting in Social Interaction, ed. by P. Drew, E. Couper-Kuhlen, 269-302. Amsterdam/Philadelphia: John Benjamins.

Nevile, Maurice. 2015. "The embodied turn in research on language and social interaction." Research on Language and Social Interaction, 48(2): 121-151. 10.1080/08351813.2015.1025499

Ochs, Ellinor, Emanuel A. Schegloff, and Sandra A. Thompson (eds.). 1996. Interaction and Grammar. Cambridge: Cambridge University Press.

Sacks, Harvey, Emanuel A. Schegloff, and Gail Jefferson. 1974. "A simplest systematics for the organization of turn-taking for conversation." Language 50: 696-735. 10.2307/412243

Schegloff, Emanuel A. 2007. Sequence Organization in Interaction: A primer in conversation analysis. Cambridge: Cambridge University Press.

Selting, Margret, and Elizabeth Couper-Kuhlen (eds.). 2001. Studies in Interactional Linguistics. Amsterdam/Philadelphia: John Benjamins.

Streeck, Jürgen, Charles Goodwin, and Curtis LeBaron (eds.). 2011. Embodied Interaction: Language and body in the material world. Cambridge: Cambridge University Press. 
Svennevig, Jan. 2004. "Other-repetition as display of hearing, understanding and emotional stance." Discourse Studies 6(4): 489-516.

Svennevig, Jan. 2008. "Trying the easiest solution first in other-initiated repair." Journal of Pragmatics 40(2): 333-348.

Tannen, Deborah. 1987. "Repetition in Conversation: Toward a poetics of talk." Language 63(3): 574-605.

Tannen, Deborah. 1989. Talking vocies: Repetition, dialogue, and imagery in conversational discourse. Cambridge: Cambridge University Press.

Zinken, Jörg, and Arnulf Deppermann. 2017. "A cline of visible commitment in the situated design of imperative turns: Evidence from German and Polish." In Imperative Turns at Talk: The design of directives in action, ed. by M-L. Sorjonen, L. Raevaara, and E. CouperKuhlen, 27-63. Amsterdam/Philadelphia: John Benjamins. 